\title{
Prevalence and Associated Factors of Diabetes Mellitus in Benin
}

\author{
Alphonse Kpozehouen1*, François Djrolo², Charles J. Sossa ${ }^{3}$, Akpa R. Gbary4, \\ Yessito Chouehanou ${ }^{5}$, Dieudonné Fambo ${ }^{5}$, Yessouf Tchabi ${ }^{5}$, Roger Salamon ${ }^{6}$, \\ Dismand S. Houinato ${ }^{7}$ \\ ${ }^{1}$ Assistant Professor Biostatistics/Epidemiology, Institut Régional de Santé Publique, Route des Esclaves, \\ Université d'Abomey-Calavi, Ouidah, Bénin \\ ${ }^{2}$ Professor of Diabetology, Faculty of Health Sciences, Cotonou, Benin \\ ${ }^{3}$ Assistant Professor Nutrition/Public Health, Institut Régional de Santé Publique, Route des Esclaves, Université \\ d'Abomey-Calavi, Ouidah, Bénin \\ ${ }^{4}$ Associate Professor of Epidemiology/Public Health, Institut Régional de Santé Publique Route des Esclaves, \\ Université d'Abomey-Calavi, Ouidah, Bénin \\ ${ }^{5}$ Programme National de Lutte contre les Maladies non Transmissibles, Ministère de la Santé, Cotonou, Bénin \\ ${ }^{6}$ Professor of Epidemiology, ISPED, Université de Bordeaux 2, Bordeaux, France \\ ${ }^{7}$ Professor of Neurology and Epidemiology, Laboratory of Chronic and Neurological Diseases Epidemiology \\ (LEMACEN) Faculty of Health Sciences, Cotonou and National Program for Non-communicable Diseases Control, \\ Ministry of Health, Cotonou, Benin \\ Email: ${ }^{*}$ Alphonse.Kpozehouen@gmail.com
}

Received 20 May 2015; accepted 19 July 2015; published 22 July 2015

Copyright (C) 2015 by authors and Scientific Research Publishing Inc.

This work is licensed under the Creative Commons Attribution International License (CC BY).

http://creativecommons.org/licenses/by/4.0/

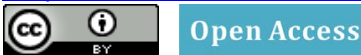

\section{Abstract}

Background: Data on diabetes mellitus in general population in Benin is scarce. This study aimed therefore to assess prevalence and risk factors of diabetes mellitus in Benin. Methods: The study consisted of a cross-sectional survey, using the World Health Organisation (WHO)'s instrument for stepwise surveillance (STEPS) of non-communicable diseases risk factors. A five-stage random sample of 25 to 64 years old male and female adults living in Benin participated in structured interviews and their size, weight and blood pressure were measured according to standardized procedures. Glycaemia was measured using ACCUTREND ${ }^{\circledR}$ test strips for capillary blood glucose. Prevalence and means were computed with their $95 \%$ confidence interval and standard error respectively, taking into account the sampling design. Prevalence was compared by $\mathrm{Khi}^{2}$ and means by Student's $t$ test. Univariate and multivariate logistic regressions were performed to identify socio-demographic diabetes's risk factors. Results: A total of 3772 adults participated in the study. The average age of respondents was 44.2 years. Overall, $68.3 \%$ of subjects were illiterate, $82.4 \%$ lived in rural areas, $82.57 \%$ were self-employed, $20 \%$ overweight, $7.51 \%$ obese and the prevalence

\footnotetext{
${ }^{*}$ Corresponding author.
}

How to cite this paper: Kpozehouen, A., Djrolo, F., Sossa, C.J., Gbary, A.R., Chouehanou, Y., Fambo, D., Tchabi, Y., Salamon, R. and Houinato, D.S. (2015) Prevalence and Associated Factors of Diabetes Mellitus in Benin. Open Journal of Epidemiology, 5, 163-173. http://dx.doi.org/10.4236/ojepi.2015.53021 
of hypertension was 29.5 p.100. The prevalence of diabetes mellitus was 1.4 p.100 [CI95\% = $(0.94: 2.05)]$. This prevalence was higher in men than in women $(2.1 \%$ vs. $0.8 \%, p=0.0031)$. This prevalence was higher in urban areas than in rural areas. The Littoral department had the highest prevalence (3.4\%), followed by the Collines department (2.7\%), Donga (2.4\%) and Borgou (2.3\%). As many as $49.3 \%$ of subjects diagnosed with diabetes mellitus were not aware of their status. The age group of 56 - 64 years had the highest risk $[O R=6.6, I C 95 \%=(1.6 ; 22.4)]$. The risk of diabetes was higher in people living in urban areas than in people living in rural areas [OR $=3.04 \mathrm{CI} 95 \%=$ (1.6; 6.0)]. After controlling for confounding factors, risk factors of diabetes were gender, men being more at risk than women $(p=0.002)$ age from 55 to 64 years $(p=0.009)$, overweight $(p<$ $0.0001)$ and obesity $(p=0.002)$. Conclusion: Our findings suggested that diabetes mellitus was common in Benin. The prevalence of diabetes is more likely to increase in regard to the nutritional transitions (diet) and the accelerating urbanization of Benin. Communication campaigns for behavioral change are needed to slow down or even reverse this trend.

\section{Keywords}

\section{Prevalence, Risk Factors, Diabetes Mellitus, Benin}

\section{Introduction}

Diabetes mellitus (DM) is a metabolic disturbance characterized by chronic hyperglycemia [1]. The global burden of DM has increased by more than a twelve times between 1985 and 2005 [2] [3]. Beside non-communicable diseases (NCD) such as cardiovascular, cancers and chronic respiratory disease, DM is becoming a major global public health problem worldwide.

In 2010, the global prevalence of DM in adults aged 20 to 79 years was estimated at 6.4 p.100 affecting 285 million adults. This prevalence could increase up to 7.7 p.100 by 2030 equaling 439 to 552 million adults with diabetes by 2030. Between 2010 and 2030 the number of adult diagnosed with DM in developing countries will experience an increase of $69 \%$ compared with only $20 \%$ in developed countries [2] [3].

Common symptoms of DM include frequent urination, excessive thirst, extreme hunger, feeling very tired much of the time and more infections than usual. Main risk factors of DM frequently reported in literature refer to: being overweight, particularly with abdominal fat distribution, inactivity, age above 40 and people of certain races including Blacks. [4] Diabetic important complications are micro and macros vascular abnormalities, as results of hyperglycemia-induced metabolic abnormalities. Macrovascular manifestations include atherosclerosis and medial calcification as well as myocardial infarction. The microvascular consequences are retinopathy, nephropathy and peripheral neuropathy that led to blindness, end-stage renal failure and foot ulcers [5].

In sub-Saharan Africa, an estimated 12.1 million people lived with DM in 2010 and an estimated increase of 23.9 million is expected in 2030. Diabetes mellitus is the most common form of diabetes that accounts for 90\% of all diabetes cases. Nutritional transition, urbanization, physical inactivity and obesity are the common risk factors that made diabetes mellitus progression very remarkable [6]-[8].

The economic burden of DM and handicaps resulting from its complications can easily plunge families into poverty. The prevalence of diabetes as well as other non-communicable diseases (NCD) is increasing rapidly while the burden of infectious diseases remains high. Hence, this "double burden" of infectious diseases and NCD considerably undermines the efforts aimed at reducing poverty and reaching the Millenium Development Goals in various countries [9].

Despite the increase in the prevalence of DM, its complications and negative impact on the health system, few national representative studies are available in sub-Saharan Africa.

Knowledge on features and associated risk factors are needed for the early diagnostic, management and prevention of DM. This important public health problem challenges health system in developing countries [10] [11]. In addition, the disease is generally associated with higher morbidity and mortality as a result of poor control [6] [12]. In Benin, DM studies were conducted in several regions and clinical settings by Djrolo et al. [13]-[15]. However, no study was performed at the national level [13]-[16]. Our study aimed therefore to determine the prevalence and identify the factors associated with DM at the national level in Benin. 


\section{Subjects and Methods}

\subsection{Study Area}

Situated in West Africa along the Gulf of Guinea in the northern tropical portion of the Atlantic Ocean, Benin is located between latitudes 6 degrees and 12 degrees north. The country covers an area of 114,763 km². Its population has been estimated at 8,364,942 people in 2008 according to the 2002 census [17], 49\% of the popu- lation was under 15 years. Life expectancy at birth was 59.2 years. The country encompasses 12 departments, 77 townships and towns and 546 districts that are subdivided into neighborhoods or villages. The main economic activities are agriculture, crafts and informal trade. The gross domestic production (GDP) per person was estimated at 31 400FCFA or €47.94. Communicable diseases such as malaria, acute respiratory infection and diarrhea are the leading causes of morbidity and mortality. However, some non-communicable diseases such as hypertension are emerging as important health problems [18]. The health system is organized on the primary healthcare basis with a central, intermediate and peripheral level that integrates all the health programs.

\subsection{Study Design and Sampling}

The study was a cross sectional, descriptive and analytical one. The study population included adults aged 25 to 64 years who have lived in Benin for at least 6 months before the investigation date. Eligible subjects unwilling to participate, people unable to answer questions as well as pregnant women were excluded from the study.

Five stages random sampling technique was used to select subjects. Sixty districts were randomly selected according to their population based on the WHO proposed method [19]. In each selected district, a list of neighborhoods/villages was defined and half of them were selected. Then, the surveyor went in the center of the village and chose randomly on direction. In the chosen direction, one home out of two was selected. In the selected home, the households were counted and one household was selected. Within the household the investigated subject was identified according to the method of Kish [20]. It was proceeded this way until the predetermined sample size per village was obtained. Kish's method offers an advantage of equivocal selection of individuals and takes into account gender and age.

The size was determined based on precision fixed of 1.5\%, type I error of 5\%, and hypertension of 27.8\% [21]. Then 6660 individuals which means 111 (6660/60) per district were planned. The number of investigated individuals in each selected village was proportional to the size of the population. The biochemical measurements were only done in $53.3 \%$ of the selected sample owing to limited resources. Finally, blood glucose tests were done for 3683 participants.

\subsection{Data Collection}

Data collection was conducted from $1^{\text {st }}$ July to 24 August 2008. Socio-demographic data such as age, gender, profession, socio-cultural area, level of education, residence, past history of hypertension and treatment were collected using questionnaire. The urban/rural place of residence was defined according to the list of Benin Economic Analysis and Statistic Institute. The urban zones were defined as follows: the population size of at least 10,000 people, the presence of at least 4 infrastructures including post office, electrical energy distribution network, safe water distribution network, a high school/secondary school, bank and representative office of the Mayor [17].

The weight was measured using electronic weighing with $100 \mathrm{~g}$ precision; the height was measured using a caliber fathom with $0.1 \mathrm{~cm}$ precision. Blood pressure was measured by a nurse or medical student in seated subjects after a 15 minutes rest using $\mathrm{OMRON}^{\circledR}$ electronic sphygmomanometer. Three measurements were taken at 5 minutes intervals; the mean value of the last two measurements was used to define the blood pressure.

The biochemical measurements were taken early in the morning at second visit. The glycaemia was measured using ACCUTREND ${ }^{\circledR}$ test strips for capillary blood glucose. A drop of capillary blood was taken at the tip of the finger of the subject and deposited on the reactive zone of a strip initially inserted in the glucometer. The results of the blood glucose level could be read on the screen after 12 seconds in $\mathrm{mg} / \mathrm{dl}$. High blood pressure was defined by the systolic pressure of more than or equal to $140 \mathrm{mmHg}$ and/or a diastolic blood pressure of more than or equal to $90 \mathrm{mmHg}$. Subjects with hypertension were those who showed high blood pressure or subjects with known hypertensive history in dependently of investigation day blood pressure level. Body mass index (BMI) was calculated by dividing the weight in kilograms by the height in square meters. Subjects were classi- 
fied into 4 categories according to the standards of the WHO [22]. Therefore, they were considered as; slim if BMI was less than $18.5 \mathrm{~kg} / \mathrm{m}^{2}$; normal weight if BMI was between $18.5 \mathrm{~kg} / \mathrm{m}^{2}$ and $24,9 \mathrm{~kg} / \mathrm{m}^{2}$; over-weight if BMI was between $25 \mathrm{~kg} / \mathrm{m}^{2}$ and 29,99 $\mathrm{kg} / \mathrm{m}^{2}$; obesity if BMI was higher than $30 \mathrm{~kg} / \mathrm{m}^{2}$. Diabetes was defined as blood glucose $\geq 7 \mathrm{mmol} / \mathrm{L}$ (or $>1.26 \mathrm{~g} \cdot \mathrm{L}^{-1}$ ) or subject with diabetes treatment history in last 12 months.

\subsection{Statistical Analysis}

A double entry of the data was made in the software EPI DATA. The weighted analysis of the data was performed by the software STATA 12 software (STATA Corp LP, College Station, Texas). The confidence interval 95\% around the estimation of the prevalence was calculated according to the method described by Bennett et al. [23] and the estimated average with their standard deviation. Chi-squared test was used to compare the prevalence according to socioeconomic factors. Factors associated with the diabetic status in the univariate analysis at the signification level of 0.20 were introduced in a multivariate logistic model to identify risk factors of diabetes. The difference was statistically significant with p-value $<0.05$. We also took into account the potential confounding factors. Finally, the analysis was performed by taking into account the survey design.

\subsection{Ethical Considerations}

An authorization was obtained from the health officials of Benin as well as ethical approbation of the National Committee of Health Ethics prior to conducting the study. The participants were briefed on the objectives and modalities of the study and they gave their verbal consent. The confidentiality of data was assured and data was analyzed anonymously.

\section{Results}

The final sample included 3772 subjects which represented $98.7 \%$ of expected number of participants. Women represented $54.5 \%$ of the participants. The average age of the subjects involved was 44.2 years [CI95\% $=(43.2$ : 45.1)]. The subjects less than 34 years and those from 55 to 64 years were most represented $(26.8 \%$ and $31.3 \%$ respectively). More than half of the population (68.3\%) was illiterate and as fewer as $0.9 \%$ had a university level education. Self-employment (82.57\%), being housewife (8.48\%) and public service worker (3.06\%) were the most frequent occupations. The majority of subjects (82.4\%) lived in rural areas. As regards the BMI status, $20 \%$ of subjects were overweight and $7.5 \%$ obese.

\section{Prevalence of Diabetes and Associated Risk Factors}

The prevalence of diabetes was 1.4 p.100 [CI95\% = $(0: 2.1)]$. This prevalence was higher in men than in women (2.1 p.100 vs 0.8 p.100, p = 0.0031). The participants aged 45 - 54 and those 55 - 64 years had the higher prevalence (1.7 p.100 and 2.6 p.100 respectively). Almost half (49.3\%) of subjects diagnosed with diabetes did not know about their diabetes status at the time of diagnosis. $22.6 \%$ of DM patients were using insulin therapy, $43.2 \%$ reported taking oral medication, $41.5 \%$ were on a special prescribed diet regimen, and $32.3 \%$ were complying with slimming treatments.

Among subjects with DM, 22.9\% were using traditional therapies including herbal mixtures for diabetes; 22.8\% reported getting advice from traditional healers for diabetes control.

The risk of diabetes was higher in the age group 56 - 64 years [OR 6.6 CI95\% (1.6:22.4)]. The level of education was significantly associated with the likelihood of being diagnosed with diabetes $(p=0.0088)$. People with a secondary level education were significantly more at risk [OR 4.4 CI95\% (1.7:11.0) Table 1]. The Littoral region had the highest prevalence of diabetes (3.5 p.100), followed by Collines (2.7 p.100), Donga (2.4 p.100) and Borgou (2.3 p.100) regions. Mono region exhibited the lowest prevalence (0.4 p.100).

The subjects in the urban areas were more at risk of diabetes [OR 3.04 CI95\% (1.6:6.0)] and the prevalence in the urban areas was $3.1 \%$ against $1.0 \%$ in the rural areas. The prevalence of diabetes was higher among overweight or obese subjects, 3.1\% and 3.9\% respectively. Overweight subjects [OR 4.7 CI95\% $=(2.4: 9.2)$ ] and obese subjects [OR 6.1 CI95\% (2.7:13.7)] were significantly more at risk of diabetes than the subjects with normal weight. Subjects with hypertension were significantly more at risk of diabetes [OR 3.4 CI95\% $=(1.8: 6.6)$ ]

In the multivariate analysis (Table 2), men were significantly more at risk of being diabetic than women [OR 
A. Kpozehouen et al.

Table 1. Distribution of participants by their diabetic status and factors, univariate analysis STEPS Survey, Benin, 2008.

\begin{tabular}{|c|c|c|c|c|c|c|}
\hline & Total N & (\%) & Diabetes\% & OR & $95 \% \mathrm{CI}$ & $\mathrm{p}$ value \\
\hline \multicolumn{7}{|l|}{ Sex } \\
\hline Men & 1.834 & 45.50 & 2.16 & 2.94 & 1.445 .88 & 0.0031 \\
\hline Women & 1.938 & 54.50 & 0.75 & 1 & & \\
\hline \multicolumn{7}{|l|}{ Age groups (years) } \\
\hline$\leq 34$ & 1.098 & 26.78 & 0.43 & 1 & & \multirow{4}{*}{0.0067} \\
\hline $35-44$ & 921 & 23.77 & 0.66 & 1.52 & 0.3366 .87 & \\
\hline $45-54$ & 683 & 18.16 & 1.73 & 4.05 & 1.03615 .84 & \\
\hline $55-64$ & 1.070 & 31.29 & 2.56 & 6.06 & 1.64022 .36 & \\
\hline \multicolumn{7}{|l|}{ Education } \\
\hline None & 2.322 & 68.29 & 0.98 & 1 & & \multirow{4}{*}{0.0088} \\
\hline Primary school & 969 & 23.11 & 1.61 & 1.65 & 0.703 .85 & \\
\hline Secondary school & 390 & 7.69 & 4.16 & 4.36 & 1.7311 .01 & \\
\hline University & 91 & 0.91 & 2.81 & 2.91 & 0.929 .20 & \\
\hline \multicolumn{7}{|l|}{ Regions } \\
\hline Plateau & 226 & 7.16 & 1.72 & 1 & & \multirow{12}{*}{0.0804} \\
\hline Atlantique & 491 & 13.77 & 0.61 & 0.41 & 0.082 .091 & \\
\hline Alibori & 243 & 9.64 & 1.16 & 0.80 & 0.173 .56 & \\
\hline Zou & 361 & 10.36 & 1.07 & 0.73 & 0.124 .63 & \\
\hline Littoral & 330 & 1.97 & 3.54 & 2.49 & 0.738 .492 & \\
\hline Mono & 169 & 11.18 & 0.43 & 0.29 & 0.032 .750 & \\
\hline Oueme & 416 & 6.07 & 0.55 & 0.37 & 0.072 .01 & \\
\hline Couffo & 333 & 14.22 & 1.53 & 1.05 & 0.244 .69 & \\
\hline Collines & 357 & 9.36 & 2.65 & 1.85 & 0.516 .68 & \\
\hline Borgou & 374 & 4.29 & 2.32 & 1.61 & 0.445 .94 & \\
\hline Atacora & 311 & 4.50 & 1.45 & 1.19 & 0.294 .86 & \\
\hline Donga & 161 & 7.47 & 2.37 & 1.65 & 0.377 .34 & \\
\hline \multicolumn{7}{|l|}{ Location } \\
\hline Urban & 1.316 & 17.58 & 3.07 & 1 & & \multirow[t]{2}{*}{0.0012} \\
\hline Rural & 2.456 & 82.42 & 1.03 & 0.33 & .168 .6412 & \\
\hline \multicolumn{7}{|l|}{ Occupation } \\
\hline Public service workers & 133 & 3.06 & 5.16 & 1 & & \multirow{9}{*}{0.0000} \\
\hline Private service workers & 128 & 1.94 & 2.44 & 0.46 & 0.063 .346 & \\
\hline Self employed & 2.956 & 82.57 & 1.22 & 0.23 & 0.070 .73 & \\
\hline Apprentice & 12 & 0.31 & 0.00 & 1 & & \\
\hline Student & 49 & 0.88 & 0.00 & 1 & & \\
\hline Housewives & 354 & 8.48 & 0.09 & 0.01 & 0.000 .08 & \\
\hline Retired & 75 & 1.52 & 5.95 & 1.16 & 0.226 .19 & \\
\hline Unemployed & 33 & 0.46 & 1.56 & 0.29 & 0.0273 .03 & \\
\hline Others & 32 & 0.77 & 9.06 & 1.82 & 0.437 .80 & \\
\hline \multicolumn{7}{|l|}{ BMI Status } \\
\hline Normal & 2.582 & 72.51 & 0.66 & 1 & & \multirow{3}{*}{0.0012} \\
\hline overweight & 815 & 20.00 & 3.06 & 4.72 & 2.419 .23 & \\
\hline Obese & 375 & 7.51 & 3.92 & 6.09 & 2.7313 .58 & \\
\hline \multicolumn{7}{|l|}{ Abdominal obesity } \\
\hline Yes & 728 & 17.06 & 2.80 & 2.60 & \multirow{2}{*}{1.374 .92} & \multirow[t]{2}{*}{0.0040} \\
\hline No & 3.044 & 82.94 & 1.10 & 1 & & \\
\hline \multicolumn{7}{|l|}{ Hypertension } \\
\hline Yes & 1.150 & 0.2952 & 0.0274 & 3.40 & 1.776 .53 & 0.0003 \\
\hline No & 2.622 & 0.7048 & 0.0082 & 1 & & \\
\hline
\end{tabular}


Table 2. Distribution of participants by their diabetic status and factors, multivariate analysis STEPS Survey, Benin, 2008.

\begin{tabular}{|c|c|c|c|}
\hline & OR & $95 \% \mathrm{CI}$ & $\mathrm{p}$ value \\
\hline \multicolumn{4}{|l|}{ Sex } \\
\hline Men & 3.57 & 1.608 .33 & 0.002 \\
\hline Women & 1 & & \\
\hline \multicolumn{4}{|l|}{ Age groups (years) } \\
\hline$\leq 34$ & 1 & & \\
\hline $35-44$ & 1.01 & 0.224 .67 & 0.984 \\
\hline $45-54$ & 2.80 & 0.6711 .80 & 0.163 \\
\hline $55-64$ & 5.84 & 1.5622 .03 & 0.009 \\
\hline \multicolumn{4}{|l|}{ Education } \\
\hline None & 1 & & \\
\hline Primary school & 1.40 & 0.513 .84 & 0.506 \\
\hline Secondary school & 2.10 & 0.646 .91 & 0.221 \\
\hline University & 1.52 & 0.366 .35 & 0.574 \\
\hline \multicolumn{4}{|l|}{ Location } \\
\hline Urban & 1 & & \\
\hline Rural & 0.49 & 0.201 .2 & 0.118 \\
\hline \multicolumn{4}{|l|}{ Occupation } \\
\hline Public service workers & 1 & & \\
\hline Private service workers & 0.47 & 0.054 .30 & 0.503 \\
\hline Self employed & 0.59 & 0.162 .04 & 0.400 \\
\hline Apprentice & - & & \\
\hline Student & - & & \\
\hline Housewives & 0.04 & 0.0080 .24 & 0.0000 \\
\hline Retired & 0.54 & 0.074 .24 & 0.560 \\
\hline Unemployed & 0.67 & 0.058 .43 & 0.758 \\
\hline Others & 5.26 & 0.9230 .19 & 0.062 \\
\hline \multicolumn{4}{|l|}{ BMI Status } \\
\hline Normal & 1 & & \\
\hline overweight & 4.95 & 2.3710 .37 & 0.0000 \\
\hline Obese & 5.31 & 1.8415 .39 & 0.0020 \\
\hline \multicolumn{4}{|l|}{ Hypertension } \\
\hline Yes & 2.00 & & \\
\hline No & 1 & 0.944 .24 & 0.071 \\
\hline
\end{tabular}

3.6 CI 95\% = (1.6:8)]. Subjects in the age-group 55-64 years [OR 5.8 CI 95\% (1.5:22.1)] were significantly at high risk of developing diabetes. Compared to public services' workers, housewives were significantly less likely to have diabetes [OR 0.04 CI 95\% $=(0.01: 0.2)]$. Overweight subjects [OR 4.5 CI 95\% (2.4:10.4)] and obese subjects [OR 5.1 CI 95\% (1.8:15.4)] were significantly more at risk of being diabetic. Variables such as level of education, hypertension and area of residence were not statistically significant in the multivariate analysis.

\section{Discussion}

Our study was conducted according to the STEPS method recommended by the WHO for screening and monitoring non-communicable diseases' risk factors. This approach allows comparison of the results between the STEPS survey on different settings.

The absence of exhaustive database of homes and households by village explains the choice of the survey design. A representative sample was obtained, thereby allowing results inference to the Beninese population.

The prevalence of DM in our study was 1.4 p.100 [CI 95\% = $(0.94: 2.05)$ ]. This would yield an estimate of 78,730 to 171,481 DM cases nationwide. Such figures could be considered as a heavy burden for a developing health care system which experiences many constraints in managing existing health problems. In the general 
population, there was no link between DM and regions. However, it should be noted that the prevalence was very high in the Littoral region. This high prevalence is explained by the fact that Cotonou, the economic capital and most urbanized setting of Benin is located in this region. The prevalence reported in the literature (3 p.100) is in convergence with our results.

The prevalence of DM was higher in urban areas compared to rural areas. Our report agrees with the observations by Baldé et al. [24], Larbi et al. [25] and Zaoui et al. [26]. In urban areas, people have a sedentary lifestyle and they adopt unhealthy diet that trigger the onset of amongst others chronic nutrition-related disease including diabetes. Men were at a higher risk than women and that conforms to results found by Zaoui et al. [26]. Our result seems sparadoxical, even if Djrolo et al. [14] and Ozturk et al. [27] have also observed prevalence higher in men [13] [26] [27]. Indeed, in Africa, women are generally overweight because people believe that being overweight is an external sign of beauty and wealth. This can also be explained by the fact that before menopause, the sexual hormones have a protective effect in women against chronic diseases. During menopause, these hormones are produced in much more reduced quantity and this reverses the risk between women and men [28] [29]. Housewives were at a lesser risk for DM than public service workers. This could be explained by the fact that public service workers are more stressed than housewives [30] or more sedentary.

Almost half of subjects diagnosed with DM were not aware of their status. This points out poor monitoring of DM that can lead to microvascular complications causing blindness, nephropathy, neurological problems and even cardiovascular complications and result in limb amputations and cardiovascular diseases [12]. Most of these complications are irreversible and costly to manage. Yet, most of developing countries such as Benin do not have adequate health facilities [31]. Diabetes is a chronic disease and diabetic subjects need access to continued medical support. This support involves intervention of medical treatment [32], equipment such as strips to measure blood glucose and, above all, health professionals, well trained in the diagnosis and management of diabetes and its complications [33].

However, two thirds of people with diabetes who live in low and mid level income countries have poor control of their diabetes due to insufficient access to care. Indeed, the availability of oral anti diabetic medicine and insulin is discontinued in many parts of the world [34]. This situation affects particularly vulnerable groups like women, children and isolated communities.

While in developed countries, diabetic care is mainly prescribed in the medical care centers, another approach prevails in Benin and African countries. Several people with diabetes often supplement treatment proposed in clinics and hospitals [35] by a traditional practitioner advice. That often distorts the prescriptions made by the health personnel and in turn makes the diabetic patients unable to observe the prescriptions of the health personnel. To overcome these problems, the traditional practitioners could receive medical training which can enable them to assist the DM patients in their follow up.

Since most of specialized centers for management of DM are not readily available in Benin and Sub-Saharan Africa, communication for behavioral change should be emphasized [36] [37]. Indeed, several DM risk factors are amenable to change. These include modifying diet, increasing physical exercise and losing weight and checking regularly one's DM status [37] [38]. The communication programs should help people to evaluate their risk for DM and to access to suitable promotional, preventive interventions and treatment [38] [39].

\section{Conclusions}

Our study shows that DM is common in Benin general population. This prevalence of diabetes is more likely to increase steadily in conjunction with the nutritional transitions and the accelerating urbanization of Benin. Except for gender and age, the risk factors associated with diabetes that we have found lend themselves to communication campaigns.

As a result, the primary prevention through lifestyle changes can play a major role in the control of DM. In the framework of non-communicable diseases control, communication campaigns for behavioral change such as maintaining right weight and regular control of blood glucose in people above 45 years, particularly in urban dwellers are needed to slow down, and even reverse this trend. The results of our study will equally serve as baseline data for periodic monitoring of the prevalence of DM in Benin.

\section{References}

[1] Zaoui, S., Biemont, C. and Meguenni, K. (2007) Epidemiology of Diabetes in Urban and Rural Regions of Tlemcen (Western Algeria). Sante, 17, 15-21. 
[2] Shaw, J., Sicree, R. and Zimmet, P. (2010) Global Estimates of the Prevalence of Diabetes for 2010 and $2030 . \mathrm{Di}-$ abetes Research and Clinical Practice, 87, 4-14. http://dx.doi.org/10.1016/j.diabres.2009.10.007

[3] Whiting, D., Guariguata, L., Weil, C. and Shaw, J. (2011) IDF Diabetes Atlas: Global Estimates of the Prevalence of Diabetes for 2011 and 2030. Diabetes Research and Clinical Practice, 94, 311-321. http://dx.doi.org/10.1016/j.diabres.2011.10.029

[4] Goldney, R., Phillips, P., Fisher, L. and Wilson, D. (2004) Diabetes, Depression, and Quality of Life: A Population Study. Diabetes Care, 27, 1066-1070. http://dx.doi.org/10.2337/diacare.27.5.1066

[5] Creager, M. and Lüscher, T. (2003) Diabetes and Vascular Disease Pathophysiology, Clinical Consequences, and Medical Therapy: Part I. Circulation, 108, 1527-1532. http://dx.doi.org/10.1161/01.CIR.0000091257.27563.32

[6] Hall, V., Thomsen, R., Henriksen, O. and Lohse, N. (2011) Diabetes in Sub Saharan Africa 1999-2011: Epidemiology and Public Health Implications. A Systematic Review. BMC Public Health, 11, 564-576. http://dx.doi.org/10.1186/1471-2458-11-564

[7] Levitt, N. (2008) Diabetes in Africa: Epidemiology, Management and Healthcare Challenges. Heart, 94, $1376-1382$. http://dx.doi.org/10.1136/hrt.2008.147306

[8] Sicree, R., Shaw, J. and Zimmet. (2009) The Global Burden, Diabetes and Impaired Glucose Tolerance. IDF Diabetes Atlas Fourth Edition, International Diabetes Federation, Brussels.

[9] Fédération Internationale du Diabète (2011) Atlas du diabète de la FID.

[10] Guariguata, L., Whiting, D., Weil, C. and Unwin, N. (2011) The International Diabetes Federation Diabetes Atlas Methodology for Estimating Global and National Prevalence of Diabetes in Adults. Diabetes Research and Clinical Practice, 94, 322-332. http://dx.doi.org/10.1016/j.diabres.2011.10.040

[11] Vandenheede, H., Deboosere, P., Gadeyne, S. and De Spiegelaere, M. (2012) The Associations between Nationality, Fertility History and diabetes-Related Mortality: A Retrospective Cohort Study in the Brussels-Capital Region (20012005). Journal of Public Health, 34, 100-107. http://dx.doi.org/10.1093/pubmed/fdr045

[12] Alberti, K. and Zimmet, P. (1998) Definition, Diagnosis and Classification of Diabetes Mellitus and Its Complications. Part 1: Diagnosis and Classification of Diabetes Mellitus. Provisional Report of a WHO Consultation. Diabetic Medicine, 15, 539-553. http://dx.doi.org/10.1002/(SICI)1096-9136(199807)15:7<539::AID-DIA668>3.0.CO;2-S

[13] Djrolo, F., Amoussou Guenou, K.D., Zannou, D.M., Houinato, D., Ahouandogbo, F. and Houngbe, F. (2003) Prévalence du diabète sucré au Bénin. Louvain Medical, 122, S258-S262.

[14] Djrolo, F., Gbary, A., Houinato, D., Fambo, D. and Djigbenoudé, O. (2011) Prevalence of Diabetes Mellitus and Associated Factors in the General Population in Benin. World Diabetes Congress.

[15] Djrolo, F., Houinato, D., Gbary, R.V.A., Djigbénoudé, O. and Sègnon, J. ( 2012) Prévalence du diabète sucré dans la population adulte à Cotonou, Bénin. Médecine des maladies Métaboliques, 6, 167-169.

[16] Wild, S., Roglic, G., Green, A., Richard, S. and King, H. (2004) Global Prevalence of Diabetes. Estimates for the Year 2000 and Projections for 2030. Diabetes Care, 27, 1047-1053. http://dx.doi.org/10.2337/diacare.27.5.1047

[17] Institut National de la Statistique et de l’Analyse économique du Bénin (2002) Rapport du 3ème Recensement Général de la Population et de l’Habitat au Bénin en 2002 INSAE, Bénin, Cotonou.

[18] Houinato, D., Gbary, A., Houehanou, Y., Djrolo, F., Amoussou, M., Segnon-Agueh, J., Kpozehouen, A. and Salamon, R. (2012) Prevalence of Hypertension and Associated Risk Factors in Benin. Revue d'Épidémiologie et de Santé Publique, 60, 95-102. http://dx.doi.org/10.1016/j.respe.2011.09.010

[19] Organisation mondiale de la Santé, Le Manuel de Surveillance STEPS de l’OMS (2005) L'approche STEPWISE de l'OMS pour la surveillance des facteurs de risque des maladies chroniques. Organisation mondiale de la Santé, Genève.

[20] Berthier, C., Caron, N. and Neros, B. (1998 ) La méthode de Kish: les problèmes de réalisation du tirage et de son extrapolation. Méthodologie Statistique, No. 9810, INSEE, Paris.

[21] Akoha, E. (2007 ) Prévalence de l’hypertension artérielle en population générale à Cotonou en 2007. Thèse de médecine, Faculté des Sciences de la Santé, Cotonou.

[22] WHO (2000) Obesity: Preventing and Managing the Global Epidemic. Geneva.

[23] Bennett, S., Woods, T., Liyanage, W. and Smith, D. (1991) A Simplified General Method for Cluster Sample Surveys of Health in Developing Countries. World Health Statist Quart, 44, 98-106.

[24] Baldé, N., Diallo, I., Baldé, M., Barry, I., Kaba, L., Diallo, M., Kaké, A., Camara, A., Bah, D., Barry, M., Sangaré-Bah, M. and Maugendre, D. (2007) Diabetes and Impaired Fasting Glucose in Rural and Urban Populations in Futa Jallon (Guinea): Prevalence and Associated Risk Factors. Diabetes \& Metabolism, 33, 114-120.

[25] Larbi, L., Erofile, G. and Alessandra, F. (2014) Diabetes in Algeria and Challenges for Health Policy: A Literature Re- 
view of Prevalence, Cost, Management and Outcomes of Diabetes and Its Complications. Globalization and Health, 10, 11.

[26] Zaoui, S., Biémont, C. and Meguenni, K. (2007) Approche épidémiologique du diabète en milieu urbain et rural. Cahiers d'études et de Recherches Francophones, 17, 15-21.

[27] Ozturk, Y., Aykut, M., Kelestimur, F., Gunay, O., Cetinkaya, F., Ceyhan, O. and Egri, M. (2000) Prevalence of Diabetes Mellitus and Affected Factors in the District of Kayseri Health Group Area. Turkish Journal of Medical Sciences, 30, 181-185.

[28] Polk, D. and Naqvi, T. (2005) Cardiovascular Disease in Women: Sex Differences in Presentation, Risk Factors, and Evaluation. Current Cardiology Reports, 7, 166-172. http://dx.doi.org/10.1007/s11886-005-0072-9

[29] Silander, K., Alanne, M., Kristiansson, K., Saarela, O., Ripatti, S., Auro, K., Karvanen, J., Kulathinal, S., Niemelä, M., Ellonen, P., Vartiainen, E., Jousilahti, P., Saarela, J., Kuulasmaa, K., Evans, A., Perola, M., Salomaa, V. and Peltonen, L. (2008) Gender Differences in Genetic Risk Profiles for Cardiovascular Disease. PLoS ONE, 3, e3615. http://dx.doi.org/10.1371/journal.pone.0003615

[30] Pouwer, F., Kupper, N. and Adriaanse, M. (2010) Does Emotional Stress Cause Type 2 Diabetes Mellitus? A Review from the European Depression in Diabetes (EDID) Research Consortium. Discovery Medicine, 9, 112-118.

[31] Alla, M. (2008) Diabetes in Sub-Saharan Africa: Kenya, Mali, Mozambique, Nigeria, South Africa and Zambia. International Journal of Diabetes in Developing Countries, 28, 101-108. http://dx.doi.org/10.4103/0973-3930.45268

[32] Beran, D., McCabe, A. and Yudkin, J. (2008) Access to Medicines versus Access to Treatment: The Case of Type 1 Diabetes. Bulletin of World Health Organization, 86, 648-649. http://dx.doi.org/10.2471/BLT.07.048710

[33] Beran, D. and Yudkin, J. (2010) Looking beyond the Issue of Access to Insulin: What Is Needed for Proper Diabetes Care in Resource-Poor Settings. International Diabetes Federation, Brussels.

[34] Deeb, L., Tan, M. and Alberti, K. (1994) Insulin Availability among International Diabetes Federation Member Associations. Diabetes Care, 17, 220-223. http://dx.doi.org/10.2337/diacare.17.3.220

[35] World Health Organization (2002) Traditional Medicine Strategy 2002-2005. WHO, Geneva.

[36] Gill, G., Mbanya, J.-C., Ramaiya, K. and Tesfaye, S. (2009) A Sub-Saharan African Perspective of Diabetes. Diabetologia, 52, 8-16. http://dx.doi.org/10.1007/s00125-008-1167-9.

[37] Omoleke, S. (2013) Chronic Non-Comunicable Diseases as a New Epidemic in Africa: Focus on the Gambia. The Pan African Medical Journal, 14, 87.

[38] Tan, A., Wan, S. and Wong, M. (1997) Patient Education in the Management of Diabetes Mellitus. Singapore Medical Journal, 38, 156-160.

[39] Maina, W., Njenga, E. and Muchemi, E. (2010) Knowledge, Attitude and Practices Related to Diabetes among Community Members in Four Provinces in Kenya: A Cross-Sectional Study. The Pan African Medical Journal, 7, 15-18. 